\title{
İskemik İnme Hastalarında Kan Lipid Parametreleri ve İntraserebral Hemoraji Gelişimi Arasındaki İliş̧ki
}

\section{The Relationship Between Blood Lipid Parameters and Development of Intracerebral Hemorrhage in Ischemic Stroke Patients}

\author{
Kamile Yücel $^{1 *}$, Fettah Eren ${ }^{2}$ \\ ${ }^{1}$ KTO Karatay Üniversitesi, Sağlık Bilimleri Yüksek Okulu, Tıbbi Biyokimya, Konya Türkiye \\ ${ }^{2}$ Sağlık Bilimleri Üniversitesi, Konya Eğitim ve Araştırma Hastanesi, Nöroloji A.D., Konya, Türkiye \\ e-mail: kamile_yucel@hotmail.com,dreren42@hotmail.com \\ ORCID: 0000-0003-4088-8932 \\ ORCID: 0000-0001-6834-0827 \\ *Sorumlu yazar/ Corresponding Author: Kamile Yücel \\ Gönderim Tarihi / Received: 02.11.2020 \\ Kabul Tarihi / Accepted: 01.05.2021 \\ DOI: $10.34087 /$ cbusbed. 819759 \\ Öz
}

Giriş ve Amaç: Çalışmada iskemik inme hastalarında hemorajik transformasyon (HT) gelişimi ile kan lipid parametrelerinin ilişkisinin incelenmesi amaçlanmıştır.

Gereç ve Yöntemler: Çalışma için 2015-2020 yılları arasında nöroloji kliniğinde yatarak tedavi alan akut iskemik inme hastaları retrospektif olarak değerlendirildi. Hastalar iskemik dokuda hemorajik transformasyon olan ve olmayan hastalar olarak 2 gruba ayrıldı. Hastaların lipid profili (trigliserid, total kolesterol, LDL kolesterol ve HDL kolesterol) 12 saat açlık sonrası, saat 5:00-07:00 arası alınan kan örnekleri ile değerlendirildi.

Bulgular: Çalışmada iskemik dokuda HT gelișen (40) ve HT gelişmeyen (60) 100 hasta dahil edildi. Gruplar arasında DM (p: 0.229) ve hipertansiyon (p: 0.698) açısından farklılık yoktu. Gruplar arasında trigliserit (p: 0.266) ve HDL (p: 0.718) açısından anlamlı fark yokken, HT gelişen hasta gurubunda total kolesterol (p: 0.017) ve LDL kolesterol (p: 0.015) seviyeleri gelişmeyen hasta gurubuna göre yüksekti ve aradaki fark anlamlıydı.

Sonuç: Çalışmamızda kan lipid parametreleri ve prognoz arasında bir ilişki gözlenmedi. Fakat hemorajik transformasyon gelişen inme hastalarında LDL kolesterol ve total kolesterol düzeylerinin hemorajik transformasyon gelişmeyen iskemik inme hastalarına göre anlamlı yüksek olduğunu bulduk. Ancak bunun klinik olarak önemli bir etkiye yol açıp açmadığını belirlemek için bulgularımızın, örneklem büyüklüğünün genişletilerek doğrulanması gerekmektedir.

Anahtar kelimeler: Hemorajik transformasyon, İskemik inme, Lipidler, Risk faktörleri

\section{Abstract}

Objective: The aim of this study was to investigate the relationship between the development of hemorrhagic transformation (HT) and blood lipid parameters in patients with ischemic stroke.

Materials and Methods: For the study, patients with acute ischemic stroke who received inpatient treatment in the neurology clinic between 2015-2020 were evaluated retrospectively. The patients were divided into 2 groups as patients with and without hemorrhagic transformation in ischemic tissue. The lipid profile of the patients (triglyceride, total cholesterol, LDL cholesterol and HDL cholesterol) was evaluated with blood samples taken between 5:00 and 7:00 hours after 12 hours of fasting.

Results: In the study, 100 patients who developed HT in ischemic tissue (40) and did not develop HT (60) were included. There was no difference between the groups in terms of DM (p: 0.229) and hypertension (p: 0.698). While there was no significant difference between the groups in terms of triglycerides (p: 0.266) and HDL (p: 0.718), the levels of total cholesterol (p: 0.017) and LDL cholesterol (p: 0.015) were higher in the patient group who developed HT compared to the non-developed patient group, and the difference was significant.

Conclusion In our study, no relationship was observed between blood lipid parameters and prognosis. However, we found that LDL cholesterol and total cholesterol levels were significantly higher in stroke patients with hemorrhagic 
transformation compared to ischemic stroke patients without hemorrhagic transformation. However, to determine whether this has had a clinically significant effect, our findings need to be confirmed by expanding the sample size.

Keywords: Hemorrhagic transformation, Ischemic stroke, Lipids, Risk factors.

\begin{abstract}
1. Giriş
İnme, nörolojik hastalıklar içerisinde geniş oranda görülen, ciddi mortalite ve morbiditeye yol açan major bir sağlık problemidir. Dünya sağlık örgütü kriterlerine göre inme, ani gelişen, 24 saatten uzun süren, ölümle sonuçlanabilen, görünürde vasküler nedenler dişında başka bir nedeni bulunmayan nörolojik defisitler olarak tanımlanmaktadır. Toplumlar arası farklılık göstermekle birlikte, epidemiyolojisinde coğrafya ve toplumların kendine ait özellikleri (yaş, cinsiyet, 1rk gibi) önem kazanmaktadır [1,2].
\end{abstract}

İnme etyolojisine yönelik yapılan sinıflandırmalar, genellikle lezyonun patolojisine göre yapılarak iskemik ve hemorajik olmak üzere 2 ana başlık altında toplanmıştır [3]. İskemik inme tüm felç vakalarının \%8085 'ini oluşturmaktadır. Etyolojide en sık kardiyoembolik ve aterotrombotik sebepler yer alır. Aterotrombotik iskemik inme, damar içinde plak ve yağ birikimlerinin sonucunda oluşan pıhtıdan kaynaklanır ve fokal serebral, spinal veya retinal enfarkt sonucu gelişen nörolojik disfonksiyon durumudur. Beyin iskemik toleransı sınırlı olan bir dokudur. Global iskemi sirasında yani beyni besleyen damarlarda kan akımı kesildiği zaman iskemiye hassas bölgelerde dakikalar içinde kalıcı hasar meydana gelir. Vasküler bir olay sonucunda meydana gelen, travmatik olmayan ve santral sinir sisteminde hasara neden olan intrakraniyal kanamalar, hemorajik inme olarak adlandırılır $[2,4,5]$.

İskemik inme risk faktörleri incelendiğinde değiştirilebilen ve değiştirilemeyen risk faktörleri olarak iki alt gruba ayrılır. Yaş, cinsiyet ve ırk değiştirilemeyen risk faktörleri, diyabet, hipertansiyon, kalp-damar hastalıkları, obezite, ateroskleroz, dislipidemi, sigara ve alkol kullanımı ise değiştirilebilir risk faktörleri arasında yer almaktadır [6]. İnme insidansının azaltılmasında, değiştirilebilir risk faktörleri, tedavi edilebilmesi ve kontrol altına alınabilmesi açısından değerlidir. İnme insidansı, sağlıklı popülasyondaki sigara, obezite, hareketsizlik, sağlıksız diyetler ve aşırı alkol alımı gibi risk faktörlerinin ortadan kaldırılması ve inme için bilinen hipertansiyon, diyabet, kalp hastalığ pıhtılaşma bozuklukları, inflamasyon gibi risk faktörlerinin tedavi edilmesi ile azaltılabilir [7-9].

İskemik inme sırasında, damarlara konumlanan kan pıhtısı, beyin fonksiyonlarının kaybını hızlandırır. Damar reperfüzyonundan sonra kan-beyin bariyerinin bozulması hemorajik transformasyona (HT) yol açar $[10,11]$. HT, iskemik inme hastalarında yaygın bir komplikasyondur. Mortalite ve morbidite üzerinde de olumsuz etkileri vardır. İskemik inme sonrası hemorajik transformasyon prevalansı iskeminin büyüklüğü başta olmak üzere birçok etmene göre büyük ölçüde değişir [12-14].

Bu bilgiler ışığında, iskemik inme hastalarında hemorajik transformasyon gelişimi ile kan lipid parametreleri arasındaki ilişkisinin incelenmesi amaçlanmıştır. Yapılan çalışmaların çoğu, iskemik inme ve hemorajik inme hastalarındaki kan lipid parametreleri üzerinedir. Bizim çalışmamız ise, iskemik inme hastalarında başvuru anındaki kan lipid parametrelerinin hemorajik transformasyon gelişimi ile ilişkili olup olmadığının değerlendirilmesi esasına dayanmaktadır. $\mathrm{Bu}$ açıdan diğer çalışmalardan farklıdır.

\section{Materyal ve Metot}

Çalışma için 2015-2020 yılları arasında nöroloji kliniğinde yatarak tedavi alan akut iskemik inme hastaları retrospektif olarak değerlendirildi. İskemik inme ile hastaneye yatan, takiplerinde hemorajik transformasyon gelişen 40 ve hemorajik transformasyon gelişmeyen 60 hastanın verileri incelendi. Hastaların klinik ve radyolojik özellikleri değerlendirildi. İskemik inme tanısı klinik özellikler ve difüzyon manyetik rezonans görüntüleme (MRG) ile doğrulandı.

\subsection{Dahil edilme kriterleri}

1. Klinik muayene ve radyolojik görüntüler ile iskemik inme tanısı doğrulanmış ve nöroloji servisinde yatarak takip edilmiş olmak

2. Başvuru sistolik kan basıncı 185 ve altı, diyastolik kan basınc1 110 ve altı olmak

3. Kan lipid parametreleri eksiksiz olmak

2.2.Dişlama kriterleri

1. Beyin bilgisayarlı tomografi (BBT) ile başlangıçta intraserebral kanaması olmak

2. İskemik inme nedeni ile intravenöz tromboliz işlemi ve nörovasküler girişimsel işlemler yapılmış olmak

3. Hiperlipidemi tanısı olup anti-hiperlipidemi tedavi almış veya almakta olmak

4. Karaciğer ve böbrek ve yetmezliği tanısı almış olmak Hastaların kronik hastalıkları (hipertansiyon ve diyabetes mellitus (DM)), sigara ve alkol kullanım durumları sorgulandı. Hipertansiyon ve DM açısından daha önceden tanı konulmuş olan ve tedavi altındaki hastalar da çalışmaya dahil edildi. Ancak tanısı olmayıp klinikte takipler sirasinda hipertansiyon ve DM tanisi konulan hastalara aşağıdaki kriterlere göre tanı konuldu.

Hipertansiyon tanısl

Joint National Committe 7 (JNC 7) ölçütleri temel alınarak; beş dakikalık aralarla yapılan üç ölçümün ortalama değerleri 140/90 mmHg üzerinde saptanan ya da daha önce antihipertansif tedavi başlanmış hastalar hipertansif olarak değerlendirildi (15).

\section{DM tanisl}

American Diyabetes Association (ADA) ve European Diyabetes Policy Group (EDPG) tarafından önerilen tanı göstergeleri temel alınarak iki ölçümde en az 8 saatlik açlık kan şekeri düzeyleri $126 \mathrm{mg} / \mathrm{dl}$ üzerinde olan, HBA1c değeri 6.5 üzerinde olan ya da antidiyabetik tedavi başlanmış olan hastalar DM olarak değerlendirildi (16).

İskemi lokalizayonu; anterior ve posterior vasküler tutulum olarak 2 gruba ayrıldı. Başvurudaki sistolik ve 
diyastolik kan basıncı değerleri kaydedildi. Hastaların lipid profili (trigliserid, total kolesterol, LDL kolesterol ve HDL kolesterol) 12 saat açlık sonrası, saat 5:00-07:00 arası alınan kan örnekleri ile değerlendirildi. Kan örnekleri hastaların yatışından sonraki gün antebrakial ven yolu ile elde edildi.

Hastaların intraserebral hemoraji durumu, klinik durumunda kötüleşme olması durumunda hemen veya rutin olarak taburculuk öncesi (3 gün-30 gün) çekilen BBT ile değerlendirildi. Hastalar iskemik dokuda hemorajik transformasyon olan ve olmayan hastalar olarak 2 gruba ayrıldı. Ayrica kanama lokalizasyonu (bazal ganglion, talamik bölge, lober, beyin sap1, serebellar) ve ventiküler sisteme açılma durumu da değerlendirildi.

Hastaların lipid profili ve intraserebral hemoraji gelişimi arasındaki ilişkisi incelendi.

Çalışma için KTO Karatay Üniversitesi Tıp Fakültesi İlaç ve Tıbbi Cihaz Dışı Araştırmalar Etik Kurul Başkanlığı'ndan onay alındı (Sayı: 2020/008, Tarih: 10.09.2020).

\subsection{Istatistiksel Analiz}

Veri toplama aşaması sonunda elde edilen veriler bilgisayar ortamına aktarılarak analiz edildi. Analiz için SPSS 15.0 (SPSS Inc., Chicago, IL, USA) paket programı kullanıldı. Verilerin normal dağılıma uygunluğu görsel (histogram ve olasılık grafikleri) ve analitik yöntemler (Kolmogrorov-Smirnov/ShapiroWilk testleri) kullanılarak incelendi. Sayısal verilerin özetlenmesinde; aritmetik ortalama, standart sapma, minimum ve maximum değerleri, kategorik verilerin özetlenmesinde frekans dağılımları ve yüzdelikler kullanıldı. Kategorik verilerin karşılaştırılamasında kikare testi veya Fisher testi kullanıldı. Sayısal verilerle kategorik değişkenler arasındaki ilişki Student- $\mathrm{T}$ ve Man-Whitney U testleri ile değerlendirildi. 3 ve daha fazla grubun sayısal verilerle değerlendirilmesinde Kruskal Wallis testleri kullanıldı. Kruskal Wallis testi sonucu anlamlı olan gruplar arasında ikili karşılaştırmalar için posthoc Man-Whitney U testi ve Bonferroni düzeltmesi yapıldı. Normal dağılmayan sayısal değişkenlerin korelasyonları Spearman korelasyon katsayısı ile analiz edildi. ROC analizi sonucu eğri altında kalan alan (AUC) olarak verildi. İstatistiksel anlamlılık için tip-1 hata düzeyi $\% 5$ olarak kabul edildi.

\section{Bulgular ve Tartışma}

3.1.Bulgular

$\mathrm{Bu}$ çalışmaya 2015-2020 yılları arasında nöroloji kliniğinde iskemik inme tanısı almış, iskemik dokuda HT gelişen (40) ve HT gelişmeyen (60) 100 hasta dahil edildi. Çalışmada 18-93 yaş arasında 41 kadın ve 59 erkek hasta vardı. HT gelişen gruptaki hastaların yaş ortalaması $66.47 \pm 13.14$, HT gelişmeyen gruptaki hastaların yaş ortalaması $64.78 \pm 17.28$, idi ve çalışmamızda inme geçirenlerin \%60'1 65 yaş üzerindeydi. HT gelişen gruptaki hastaların 18'ini (\%45) kadın, 22'sini (\%55) erkek hastalar oluştururken, HT gelişmeyen gruptaki hastaların 23'ünü kadın (\%38.3), 37 'sini (\%61.7) erkek hasta oluşturmaktaydı ve gruplar arasında yaş ortalaması (p: 0.580) ve cinsiyet (p: 0.507) açısından anlamlı bir fark yoktu. Hastaların anemnezlerine göre 22 hastada (\%22) sigara, 4 hastada (\%4) alkol kullanımı vardı.

Hemorajik transformasyon gelişen grupta 6 adet DM $(\% 15), 10$ adet hipertansiyon (\%25) hastası yer alırken, HT gelişmeyen grupta 15 adet DM (\%25), 13 adet hipertansiyon (\%21.7) hastası bulunmaktaydı ve gruplar arasinda DM (p: 0.229) ve hipertansiyon (p: 0.698) açısından farklılık yoktu. Grupların temel karakteristikleri Tablo 1'de verilmiştir.

Tablo 1. Hemorajik transformasyon gelişen ve gelişmeyen inme gruplarının demografik özellikleri

\begin{tabular}{|c|c|c|c|c|}
\hline Değişkenler & $\begin{array}{l}\text { Toplam } \\
\text { (n: 100) }\end{array}$ & $\begin{array}{c}\text { HT gelişen } \\
\text { (ort } \pm \text { SS) (n: 40) }\end{array}$ & $\begin{array}{l}\text { HT gelişmeyen } \\
\text { (ort } \pm \text { SS) (n: 60) }\end{array}$ & $\begin{array}{c}\mathbf{p} \\
\text { value }\end{array}$ \\
\hline Yaş ortalaması & $65.46 \pm 15.70$ & $66.47 \pm 13.14$ & $64.78 \pm 17.28$ & 0.580 \\
\hline Cinsiyet (K/E) & $41 / 59$ & $18 / 22$ & $23 / 37$ & 0.507 \\
\hline Sigara $(\mathbf{V} / \mathbf{Y})$ & $22 / 78$ & $6 / 34$ & $16 / 44$ & 0.168 \\
\hline Alkol (V/Y) & $4 / 96$ & $2 / 38$ & $2 / 58$ & $*$ \\
\hline Diyabet (V/Y) & $21 / 79$ & $6 / 34$ & $15 / 45$ & 0.229 \\
\hline Hipertansiyon (V/Y) & $23 / 77$ & $10 / 30$ & $13 / 47$ & 0.698 \\
\hline
\end{tabular}


Hemorajik transformasyon gelişen grupta iskemi lokalizayonları 28 adet anterior vasküler alan, 6 adet posterior vasküler alan ve 6 adet anterior-posterior vasküler alan, HT gelişmeyen grupta iskemi lolalizasyonları, 48 adet anterior vasküler alan, 9 adet posterior vasküler alan ve 3 adet anterior-posterior vasküler alan, kanama lokalizasyonları ise 8 adet bazal gangliyon, 7 adet talamik hematom, 16 adet lober hematom, 4 adet beyin sap1 hematomu ve 5 adet serebellar hematom şeklindeydi. İskemi lokalizasyonuna göre lipid parametreleri açısından gruplar arasında yapılan kıyaslamada anlamlı bir fark yoktu $(\mathrm{p}>0.05)$.
Lipid parametreleri açısından gruplar karşılaştırıldığında; HT gelişen grupta trigliserit, total kolesterol, HDL, LDL kolesterol seviyeleri sirasiyla $137.65 \pm 64.52,195.62 \pm 45.71,39.25 \pm 8.60,127.77 \pm$ $38.74 \mathrm{mg} / \mathrm{dL}$, HT gelişmeyen grupta sirasıyla $125.35 \pm$ $62.15,171.91 \pm 42.46,38.60 \pm 8.91,107.99 \pm 38.27$ $\mathrm{mg} / \mathrm{dL}$ olarak bulundu. Gruplar arasında trigliserit (p: 0.266 ) ve HDL (p: 0.718) açısından anlamlı fark yokken, HT gelişen hasta gurubunda total kolesterol (p: 0.017) ve LDL kolesterol (p: 0.015) seviyeleri gelişmeyen hasta gurubuna göre yüksekti ve aradaki fark anlamlıyd. HT gelişen ve gelişmeyen, DM olan ve olmayan, hipertansiyonu olan ve olmayan grupların lipid profilleri açısından karşılaştırılması Tablo 2, 3 ve 4'te verildi.

Tablo 2. Hemorajik transformasyon gelişen ve gelişmeyen inme gruplarının lipid profili açısından karşılaştırması

\begin{tabular}{|l|c|c|c|}
\hline Değişkenler & HT gelişen & HT gelişmeyen & p \\
& (ort \pm SS) (n: $\mathbf{4 0})$ & (ort \pm SS) (n: 60) & 0.266 \\
\hline Trigliserit (mg/dL) & $137.65 \pm 64.52$ & $125.35 \pm 62.15$ & $0.017 *$ \\
\hline Total kolesterol (mg/dL) & $195.62 \pm 45.71$ & $171.91 \pm 42.46$ & 0.718 \\
\hline HDL kolesterol (mg/dL) & $39.25 \pm 8.60$ & $38.60 \pm 8.91$ & $0.015^{*}$ \\
\hline LDL kolesterol (mg/dL) & $127.77 \pm 38.74$ & $107.99 \pm 38.27$ & \\
\hline n: Olgu sayıs1, SS: Standart sapma, ${ }^{*}$ p $<0.05$ istatistiksel anlaml & & \\
\hline
\end{tabular}

Tablo 3. DM olan ve olmayan inme gruplarının lipid profili açısından karşılaştırması

\begin{tabular}{|l|c|c|c|}
\hline Değişkenler & DM var & DM yok & p \\
\hline Yaş & (ort \pm SS) (n: 21) & (ort \pm SS) (n: 79) & 0.218 \\
\hline Trigliserit (mg/dL) & $69.71 \pm 12.19$ & $64.33 \pm 16.39$ & 0.609 \\
\hline Total kolesterol (mg/dL) & $130.66 \pm 57.19$ & $130.16 \pm 64.89$ & 0.117 \\
\hline HDL kolesterol (mg/dL) & $168.62 \pm 44.48$ & $184.79 \pm 44.93$ & 0.108 \\
\hline LDL kolesterol (mg/dL) & $36.85 \pm 8.37$ & $39.39 \pm 8.82$ & $0.029 *$ \\
\hline n: Olgu sayis1, SS: Standart sapma, *p $<0.05$ istatistiksel anlaml & $101.07 \pm 42.86$ & \\
\hline
\end{tabular}


Tablo 4. Hipertansiyon olan ve olmayan inme gruplarının lipid profili açısından karşılaştırması

\begin{tabular}{|l|c|c|c|}
\hline Değişkenler & Hipertansiyon var & Hipertansiyon yok & p \\
& (ort \pm SS) (n: 23) & (ort \pm SS) (n: 77) & 0.765 \\
\hline Yaş & $65.60 \pm 11.36$ & $65.42 \pm 16.85$ & $0.032 *$ \\
\hline Trigliserit (mg/dL) & $156.56 \pm 70.76$ & $122.42 \pm 58.83$ & 0.104 \\
\hline Total kolesterol (mg/dL) & $188.52 \pm 39.28$ & $179.27 \pm 46.72$ & 0.369 \\
\hline HDL kolesterol (mg/dL) & $37.56 \pm 8.15$ & $39.25 \pm 8.94$ & 0.566 \\
\hline LDL kolesterol (mg/dL) & $115.17 \pm 35.97$ & $116.12 \pm 40.69$ & \\
\hline n: Olgu sayısi, SS: Standart sapma, * ${ }^{p}<0.05$ istatistiksel anlaml & & \\
\hline
\end{tabular}

Yapılan ROC analizinde eğri altında kalan alan trigliserit, total kolesterol, LDL ve HDL kolesterol için sirasıyla $0.566,0.642,0.644$ ve 0.508 olarak bulundu. $\mathrm{Bu}$ parametrelerden sadece tolal kolesterol ve LDL kolesterol için anlamlı fark elde edildi. Tolal kolesterol açısından HT gelişen ve gelişmeyen gruplar arasında yapılan ROC analizinde serum cut off değeri $\% 58.3$ duyarlılık ve $\% 60$ özgüllük ile 177.50 olarak hesaplandı $(\mathrm{p}=0.017, \mathrm{AUC}=0.642, \% 95 \mathrm{CI}=0.534-0.750) . \mathrm{LDL}$ kolesterol açısından HT gelişen ve gelişmeyen gruplar arasında yapılan ROC analizinde serum cut off değeri $\% 60$ duyarlılık ve $\% 60$ özgüllük ile 113.50 olarak hesapland $1(\mathrm{p}=0.015$, AUC $=0.644, \% 95 \mathrm{CI}=0.538$ 0.751). Lipid parametrelerine ait ROC grafiği şekil 1'de verildi.

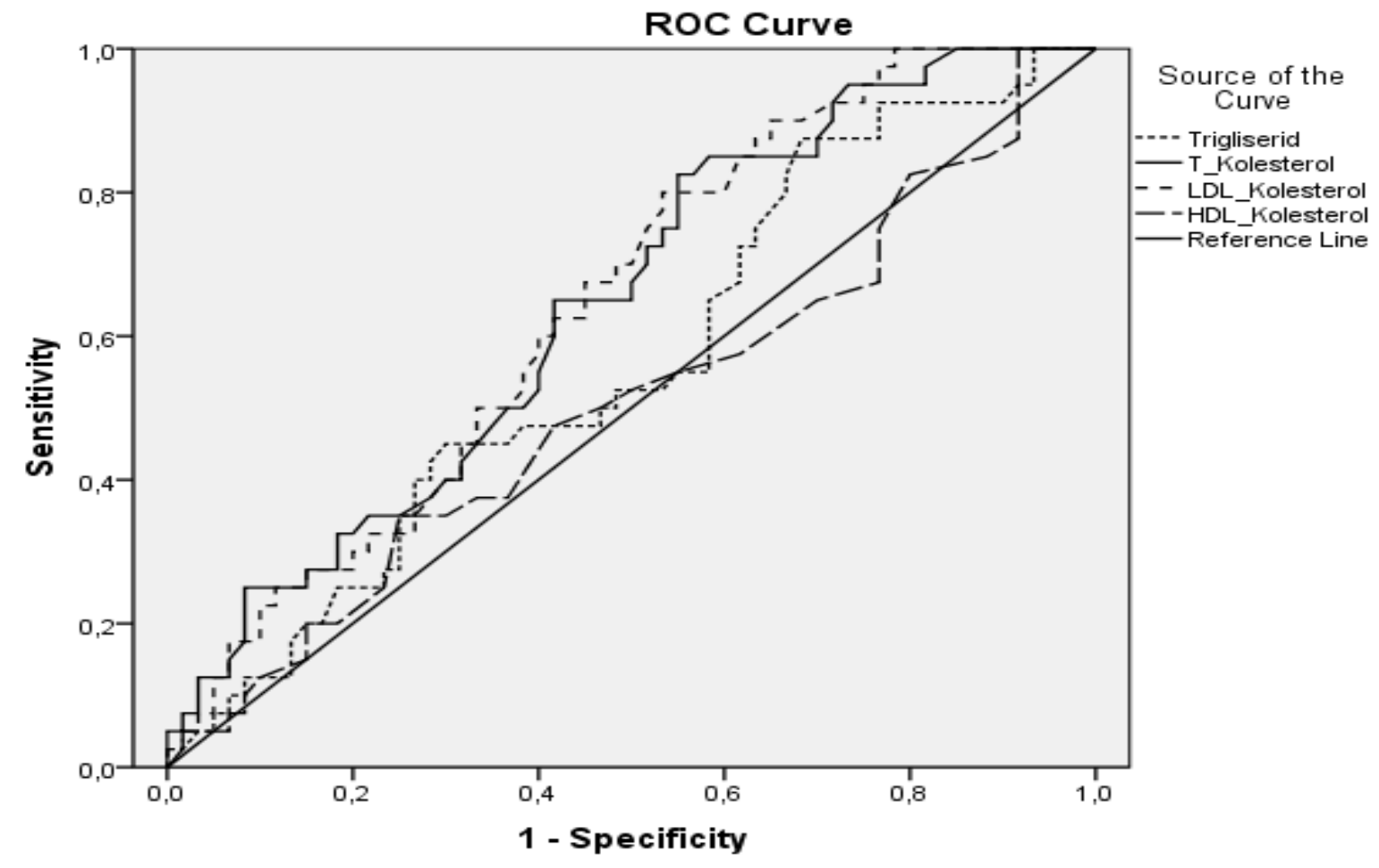

Diagonal segments are produced by ties.

Şekil 1. Lipid parametrelerine ait ROC analiz grafiği 


\subsection{Tartışma}

İnme nörolojik hastalıklar içinde geniş oranda görülen bir sağlık problemidir ve yaşla birlikte artış gösterir. Yapılan çalışmalarda HT gelişen gruplarda yaş ortalaması 61.57 $\pm 15.9,70.84 \pm 13.1$ ve $68.3 \pm 13.3$ olarak belirtilirken, HT gelişmeyen grupta $65.65 \pm 12.7,67.8 \pm 12.0$ ve 65.8 \pm 13.1 olarak belirtilmektedir [10, 17,18]. Mevcut çalışmada ise HT gelişen grupta yaş ortalaması $66.47 \pm$ 13.14, HT gelişmeyen grupta yaş ortalaması $64.78 \pm$ 17.28 bulduk ve hem HT gelişen hem de gelişmeyen grupta erkek hasta sayısı kadın hasta sayısından fazla idi. Cinsiyet açısından yapılan literatür taramalarında bu bulgularla paraleldir. Toplumların kendine ait özellikleri, inme yaş ortalamasını ve cinsiyet farklılıklarını etkilese de sonuçlarımız diğer çalışmalarla uyumludur $[10,13,17]$. Sigara içmenin HT riskini arttırdığını belirten çalışmalar bulunmaktadır. Alkol tüketimi için ise hipertansiyon ve koagülasyon artışına yol açtığı için HT gelişme riskinde artış sağladığı belirtilmektedir [19]. Bizim çalışmamızda ise HT gelişmeyen grupta sigara içme oranı diğer gruba göre daha fazla olsa da sigara ve alkol kullanımı açısından gruplar arasında anlamlı fark yoktu.

Hemorajik transformasyon etyolojisinin araştırıldı $\breve{1}$ çalışmalar, HT'a eşlik eden hastalıklar açısından DM ve özellikle hipertansiyonun ciddi risk faktörleri arasında olduğunu göstermektedir [20-22]. DM'nin inme riskini 1-3 kat kadar arttırdığı bildirilmiştir. Belirgin hiperglisemi ve DM, mikrovaskülarite üzerine hasarlandırıcı etkiler yaratabilir ve bu reperfüzyon sonrası ödem ve hemorajik transfüzyonda artışa yol açabilir [12,23]. Kuusisto ve ark. 3.5 y1l boyunca diyabeti olan 229, diyabeti olmayan 1298 kişiyi takip etmişler ve diyabetlilerde inme oranın $1 \% 6.1$, diyabeti olmayanlarda da \%3.4 olarak bildirmişlerdir [24]. Gang ve arkadaşlarının 2019 yılında 628 HT gelişmeyen ve 104 HT gelişen toplam 732 hasta ile gerçekleştirdikleri çalışmada ise acil servise geldiklerinde ölçülen kan glukoz değerlerine göre yorum yapmışlar ve kan şekerinin HT gelişimine, prognozun kötüleşmesine etki etmediğini, gruplar arası DM açısından da fark olmadığını bildirmişlerdir (p: 0.165) [10]. Deng ve arkadaşlarının 2019 yılında 155 HT gelişen ve 1268 HT gelişmeyen 2 grubu karşılaştırdıkları çalışmada, HT gelişen grupta 114 hipertansiyon, 41 DM hastas1, HT gelişmeyen grupta ise 930 hipertansiyon ve $245 \mathrm{DM}$ hastası olduğunu bildirmişlerdir. Gruplararasında hipertansiyon açısından fark yokken (p: 0.957), DM açısından farkın anlamlı olduğu (p: 0.037) ve HT gelişimi ile diyabet arasında ilişki olduğunu vurgulamışlardır [17]. Çalışmamızda DM ve hipertansiyon açısından gruplar incelendiğinde HT gelişmeyen grupta DM (\%25), HT gelişen grupta ise hipertansiyon (\%25) fazla bulunmuştur. Fakat gruplararası DM ve hipertansiyon açısından farklılık anlamlı değildi. Çalışmalar arasındaki bu farklılıkların metadolojik farklılıklardan ve hasta sayısından kaynaklandığını düşünmekteyiz. Çünkü bazı çalışmalar DM varlığına veya yokluğuna göre değerlendirme yaparken, bazı çalışmalar ise hastanın ilk andaki glukoz ölçümlerine göre grupları kıyaslamıştır.
Bizim çalışmamız için ise hasta sayısı diğer çalışmalara kıyasla azdı ve hastalara ait kan glukoz değerinden ziyade DM varlığı ve yokluğu sorgulanarak kıyaslama yapıldı. Hipertansiyon açısından hastaneye yatış anında ölçülen sistolik ve diastolik kan basıncı değerleri kullanıldı ve HT gelişen ve gelişmeyen gruplar arasında anlamlı bir fark yoktu (sirasiyla, p: 0.247, p: 0.468). Çalıșmamız için hastaların kan basıncı takip değerleri bulunmamaktadır. HT gelişiminde en önemli risk faktörü olan hipertansiyon için, hastaların kan basıncı takip değerlerine göre yorum yapılmasının daha doğru olacağ kanaatindeyiz.

Diyabetes mellitüs ve hipertansiyon gibi endotel hasarı yaratan haslalıklar için lipid profili herzaman önem taşımaktadır ve özellikle LDL kolesterolün kontrol altında tutulması önemlidir. Nomani AZ ve arkadaşları 2016 yılında 233 iskemik inme hastasını DM olan ve olmayan olarak gruplayarak lipid profilleri açısından değerlendirmişler ve gruplar arasında istatistiksel anlamlı fark olmadığını bildirmişlerdir (25). Çalışmamızda DM ve hipertansiyon açısından yaptığımız grupların lipid profillerini incelediğimizde; DM olan grupta LDL kolesterol seviyesinin, hipertansiyonu olan grupta ise trigliserit seviyelerinin anlamlı yüksek olduğunu bulduk. Lipid parametreleri ile inme arasındaki ilişki hakkında literatürdeki çalışmalar, genel olarak yüksek total kolesterol, LDL kolesterol ve düşük HDL kolesterol düzeyinin artmış inme riski ile ilişkili olabileceğini öne sürmektedir [26-28]. Bang ve arkadaşları [29], kolesterolün damar sistemi üzerine etkilerinin bilindiğini, normal zar akışkanlığı için gerekli olduğunu ve yeterli kolesterol seviyelerinin damarların bütünlügünü ve yırtılmaya karşı direncini korumak için önemli olabileceğini bildirmiştir. Dayton ve arkadaşları ise [30] total kolesterol seviyeleri ve inme riski arasında net bir korelasyon bulunmadığını belirtilmiştir.

Bizim çalışmamızla benzer nitelikte olan çalışmalar incelendiğinde ise; bazı çalışmalar, düşük total kolesterol ve LDL kolesterol seviyelerinin iskemik inme sonrası serebral kanama ve HT gelişim insidansını artırdığını, bazı çalışmalar ise kolesterol seviyesi ile HT gelişimi arasında hiçbir ilişki olmadığını bildirmiştir. Kim ve arkadaşları, LDL kolesterol düzeylerinin aterosklerotik serebral enfarktüs hastaları arasında HT ile ilişkili olabileceğini belirtmiştir [31]. Yang ve arkadaşları 2016 y1lında 35 HT olan ve 313 HT olmayan hasta grubuyla gerçekleştirdiği çalışmada, HT olan grubun daha düşük total kolesterol, HDL ve LDL kolesterol seviyelerine sahip olduğunu ve aradaki farkın istatistiksel olarak anlamlı olduğunu bulmuşlardır $(\mathrm{p}<0.05)$ [18]. Olsen ve arkadaşlarının yaptığı bir çalışma, anterior sistem akut iskemik inmelerde düşük total kolesterol ve LDLkolesterol seviyesinin hemorajik transformasyon gelişimi ile ilişkili olabileceğini bildirmiştir [32]. Uyttenboogaart ve arkadaşları, yüksek trigliserit düzeylerinin bağımsız olarak daha yüksek HT riski ile ilişkili olduğunu bulmuştur [33]. Rocco ve arkadaşlarının yaptığı prospektif bir çalışma, kan lipid düzeylerinin ve önceki statin kullanımının HT ve mortalite ile ilişkili olmadığını göstermiştir [34]. 2019 yılında Gang ve 
arkadaşları, 104 HT gelişen ve 628 HT gelişmeyen iskemik inmeli hasta grubu ile gerçekleştirdikleri çalışmada ise HT olan grupta kolesterol ve trigliserit düzeylerinin diğer gruba göre anlamlı düşük olduğunu, düşük LDL kolesterol seviyelerine sahip hastalarda kötü prognoz riskinin arttığını göstermişlerdir [10].

Mevcut çalışmamızda ise HT olan ve HT olmayan gruplarımız arasında trigliserit ve HDL kolesterol açısından anlamlı fark yokken, HT olan grupta total kolesterol ve LDL kolesterol seviyeleri, HT olmayan guruba göre yüksekti ve aradaki fark anlamlıydı. Serum lipidleri ve HT arasındaki ilişkiyi inceleyen çalışmalar çeşitli sonuçlar vermiştir ve sonuçlar tartışmalıdır. Çalışma sonuçları arasındaki farklılıkların hasta sayıları, altta yatan risk faktörleri, genetik farklllıklar, dahil edilme kriterleri ve tedavileri (örn., İntra-arteriyel tromboliz, intravenöz tromboliz, kombine tromboliz), çalışmalarda kullanılan metodolojik farklılıklar ve çalışmaların çoğunun geriye dönük çalışmalar olmasından kaynaklanabileceğini düşünmekteyiz.

İskemik ve hemorajik inme ile lipid parametrelerinin ilişkisinin incelendiği çalışma sayısı oldukça fazladır. Ancak iskemik inmede, başvuru anındaki kan lipid seviyelerinin, beyinde hemorajik transformasyon gelişimini öngörebilecek bir belirteç olması bu çalışmanın literatüre en belirgin katkısı olmaktadır. Çalışma ile özellikle LDL kolesterol ve total kolesterol seviyesinin hemorajik transformasyon gelişimi ile ilişkili olduğu ortaya konulmuştur.

Çalışmanın klsıtlılıklar

Çalışmamızda hastalarda klinik dizabilite durumu ve iskemik alan volümü gibi alt parametlere göre gruplandırma yapılmamıştır. Pirimer sonlanım noktası hemorajik transformasyon gelişmesi veya gelişmemesi olarak alınmıştır. Hematom volümü hesaplanmadığı için hematom volümü ile lipid seviyeleri arasında ilişki olup olmdığı değerlendirilememiştir. Hastalarda uzun dönem mortalite ve dizabilite durumu ile lipid seviyeleri arasındaki ilişki belirlenmemiştir. Hastalarin başvuru saati, kanların inmeden kaç saat sonra alındığı ve inme süresi ile lipid değerleri arasındaki ilişki değerlendirilmemiştir. Hastaların beslenme özellikleri, fiziksel aktivite durumu boy-kilo ve vücut kitle indeksine göre karşılaştırma yapılmamıştır.

\section{Sonuç}

İnme ile birlikte sık görülen hastalıkların (hipertansiyon, diyabet, koroner arter hastalığı) kan lipid parametrelerini ve hastalığın prognozunu etkileyebileceği gözardı edilmemelidir. Çalışmamızda kan lipid parametreleri ve prognoz arasında bir ilişki gözlenmedi. Fakat hemorajik transformasyon gelişen inme hastalarında LDL kolesterol ve total kolesterol düzeylerinin hemorajik transformasyon gelişmeyen iskemik inme hastalarına göre anlamlı yüksek olduğunu bulduk. Ancak bunun klinik olarak önemli bir etkiye yol açıp açmadığını belirlemek için bulgularımızın, örneklem büyüklüğünün genişletilerek ve ileriye dönük çoklu merkez çalışmalarının yapılarak doğrulanması gerekmektedir.

\section{Referanslar}

1. Utku, U, Çelik, Y, İnmede etyoloji, sınıflandırma ve risk faktörleri, Serebrovasküler Hastalıklar, Balkan S (Ed.). 3th ed. Ankara, Güneş Kitabevi, 2009, 85-96.

2. Yew, K.S, Cheng, E, Acute stroke diagnosis, American family physician, 2009, 80,33-40.

3. Rowland, L.P, Pedley, T.A, Serebrovasküler hastalığın patogenezi, sınıflandırılması ve epidemiyolojisi, Doğu O (Çeviri Ed.). Merritt's Neurology Türkçe 12. Baskı, Güneş Tıp Kitabevleri, İstanbul, Türkiye, 250-263, 2012.

4. Deng, Q, Li, S, Zhang, H, Wang, H, Gu, Z, Zuo, L, Wang, L, Yan, F, Association of serum lipids with clinical outcome in acute ischaemic stroke, Journal of clinical neuroscience, 2019, 59, 236244.

5. Feigin, V.L, Stroke epidemiology in the developing world, Lancet, 2005, 365, 2160-2161

6. Dhamija, R.K, Arora, S, Jais, P.G, Kaintura, A, Kumar, M, Bhattacharjee, J, Study of genetic, metabolic and inflammatory risk factors in patients of acute ischemic stroke, Indian Journal of Clinical Biochemistry, 2008, 23, 136-143.

7. Appelros, P, Stegmayr, B, Terent, A, Sex differences in stroke epidemiology: a systematic review, Stroke, 2009, 40, 1082-1090.

8. Banerjee, C, Moon, Y.P, Paik, M.C, Rundek, T, Mclaughlin, CM, Vieria, JR, Duration of diabetes and risk of ischemic stroke The Northern Manhattan Study, Stroke, 2012, 43, 1212-1217.

9. Jauch, E.C at al, Guidelines for early management of patients with acute ischemic stroke (AHA/ASA), Stroke, 2013, 44, 870-947.

10. Gang, L.V, Gou-qiang, W, Zhen-xi, X, Hai-xia, W, Nan, L, Wei, W, Influences of blood lipids on the occurrence and prognosis of hemorrhagic transformation after acute cerebral infarction: a casecontrol study of 732 patients, Military Medical Research, 2019, 6, 111

11. Krueger, M, Bechmann, I, Immig, K, Reichenbach, A, Härtig, W, Michalski, D, Blood-brain barrier breakdown involves four distinct stages of vascular damage in various models of experimental focal cerebral ischemia, Journal of cerebral blood flow and metabolism, 2015, 35, 292-303.

12. Khatri, R, McKinney, AM, Swenson, B, Janardhan, V, Blood-brain barrier, reperfusion injury, and hemorrhagic transformation in acute ischemic stroke, Neurology, 2012, 79, 52-57.

13. Paciaroni, M, Agnelli, G, Corea, F, Ageno, W, Alberti, A, Lanari, A et al., Early hemorrhagic transformation of brain infarction: rate, predictive factors, and influence on clinical outcome: results of a prospective multicenter study, Stroke, 2008, 39, 22492256.

14. Wang, B.G, Yang, N, Lin, M, Lu, B, Analysis of risk factors of hemorrhagic transformation after acute ischemic stroke: cerebral microbleeds do not correlate with hemorrhagic transformation, Cell biochemistry and biophysics, 2014, 70, 135-142.

15. Joint National Committee on Prevention, Detection, Evaluation and Treatment of High Blood Pressure, The seven report of the Joint National Committee on Prevention, Detection, Evaluation and Treatment of High Blood Pressure, Journal of the American Medical Association, 2003, 289, 2560-2572.

16. American Diabetes Association. Standarts of medical care in diabetes, Diabetes Care, 2004, 27: 15.

17. Deng, Q.W, Liu, Y.K, Zhang, Y.Q, Chen, X.L, Jiang, T, Hou, J.K, Low triglyceride to high-density lipoprotein cholesterol ratio predicts hemorrhagic transformation in large atherosclerotic infarction of acute ischemic stroke, Aging, 2019, 10, 1589-1601.

18. Yang, N, Lin, M, Wang, B.G, Zeng, W.Y, He, Y.F, Peng, HY, Low level of lowdensity lipoprotein cholesterol is related with increased hemorrhagic transformation after acute ischemic cerebral infarction, European review for medical and pharmacological sciences, 2016 20, 673-678.

19. Xing, Y, Guo, Z.N, Yan, S, Jin, H, Wang, S, Yang, Y, Increased globulin and its association with hemorrhagic transformation in patients receiving intra-arterial thrombolysis therapy, Neuroscience bulletin, 2014, 30, 469-476

20. Ntaios, G, Egli, M, Faouzi,, M, Michel P.J, Shaped association between serum glucose and functional outcome in acute ischemic stroke, Stroke, 2010, 41, 2366-2370.

21. Tapia-Pérez, J.H, Gehring, S, Zilke, R, Schneider, T, Effect of increased glucose levels on short-term outcome in hypertensive spontaneous intracerebral hemorrhage, Clinical neurology and neurosurgery, 2014, 118, 37-43. 
22. Zheng, J, Sun, Z, Zhang, X, Li, Z, Guo, X, Xie, Y, Sun, Y, Nontraditional lipid profiles associated with ischemic stroke not hemorrhagic stroke in hypertensive patients: results from an 8.4 years follow-up study, Lipids in health and disease, 2019, 18, 9.

23. Wang, Q, Wang, D, Liu, M, Is diabetes a predictor of worse outcome for spontaneous intracerebral hemorrhage? Clinical neurology and neurosurgery, 2015, 134, 67-71.

24. Kuusito, J, Mykkannen, L, Laasko, M, Non-insulin dependent diabetes and it's metabolic control are important predictors of stroke in elderly subjects, Stroke, 1994, 25, 1157-1164.

25. Nomani, AZ, Nabi, S, Ahmed, S, Iqbal, M, Rajput, H.M, Rao, S, High $\mathrm{HbA1c}$ is associated with higher risk of ischaemic stroke in Pakistan population without diabetes, Stroke and vascular neurology, 2016,5;1(3),133-139.

26. Beheshti, S, Madsen, C.M, Varbo, A, Benn, M, Nordestgaard, B.G Relationship of familial hypercholesterolemia and high LDL Cholesterol to ischemic stroke: the Copenhagen general population study, Circulation, 2018, 138, 578-589.

27. Bots, M.L, Elwood, P.C, Nikitin, Y, Total and HDL cholesterol and risk of stroke. EUROSTROKE: a collaborative study among research centres in Europe, Journal of Epidemiology and Community Health, 2002, 56, 19-24

28. Zhang, Y, Tuomilehto, J, Jousilahti, P, Wang, Y, Antikainen, R, Hu, $\mathrm{G}$, Total and high density lipoprotein cholesterol and stroke risk, Stroke, 2012, 43, 1768-1774

29. Bang, O.Y, Saver, J.L, Liebeskind, D.S, Starkman, S, Villablanca, P, Salamon, N, Cholesterol level and symptomatic hemorrhagic transformation after ischemic stroke thrombolysis, Neurology, 2007 , 68, 737-742.

30. Dayton, S, Chapman, J.M, Pearce, M.L, Popjak, G.J, Cholesterol, atherosclerosis, ischemic heart disease, and stroke, Annals of internal medicine, 1970, 72, 97-109.

31. Kim, B.J, Lee, S.H, Ryu, W.S, Kang, B.S, Kim, C.K, Yoon, B.W Low Level of Low-Density Lipoprotein Cholesterol Increases Hemorrhagic Transformation in Large Artery Atherothrombosis bu Not in Cardioembolism, Stroke, 2009, 40, 1627-1632.

32. Olsen, T.S, Christensen, R.H, Kammersgaard, L.P, Andersen, K.K Higher total serum cholesterol levels are associated with less severe strokes and lower all-cause mortality: ten-year follow-up of ischemic strokes in the Copenhagen stroke study, Stroke, 2007, 38, 2646-2651.

33. Uyttenboogaart, M, Koch, M.W, Koopman, K, Vroomen, P.C, Luijckx, G.J, Dekeyser, J, Lipid profile, statin use, and outcome after intravenous thrombolysis for acute ischaemic stroke, Jornal of Neurology, 2008, 255, 875-880.

34. Rocco, A, Sykora, M, Ringleb, P, Diedler, J, Impact of statin use and lipid profile on symptomatic intracerebral haemorrhage, outcome and mortality after intravenous thrombolysis in acute stroke, Cerebrovascular Disease, 2012, 33, 362-368.

http://edergi.cbu.edu.tr/ojs/index.php/cbusbed isimli yazarın CBU-SBED başlıklı eseri bu Creative Commons Alıntı-Gayriticari4.0 Uluslararası Lisansı ile lisanslanmıştır.

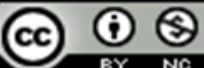

